\title{
ESTUDO DE SUBCENTROS COMERCIAIS EM PIRACICABA - SP
}

\section{STUDY OF SUB-CENTERS COMMERCIAL IN PIRACICABA - SP}

\section{ESTUDIO DE SUB-CENTROS COMERCIALES EN PIRACICABA - SP}

\author{
Silas Nogueira de Melo \\ Mestrando em Geografia, Rio Claro, IGCE, UNESP. \\ Av. 24-A, 1515 - Caixa Postal 178 - CEP: 13506-900 - Rio Claro - SP \\ silas@rc.unesp.br \\ Saulo Teruo Takami \\ Mestrando em Geografia, Rio Claro, IGCE, UNESP. \\ Rua Angelino Prezotto, 131, bairro Nova América - CEP: 13417-600 - Piracicaba - SP. \\ stakami@ piracicaba.sp.gov.br \\ Anderson Fernando Guarda \\ Analista Ambiental da Companhia de Engenharia Ambiental Caapuã etê. \\ Bacharel em Geografia, Rio Claro, IGCE, UNEP. \\ Rua João Moretti, 136, bairro Nova Piracicaba - CEP: 13405-024 - Piracicaba - SP. \\ afguarda@yahoo.com.br \\ Roberto Gabriel Cella \\ Licenciado em Geografia, Rio Claro, IGCE, UNESP. \\ Rua Visconde do Rio Branco, 1031, bairro Alto - CEP 13419-115 - Piracicaba - SP. \\ rgcella@rc.unesp.br \\ Mateus Rizato \\ Graduando em Geografia, Rio Claro, IGCE, UNESP. \\ Estagiário do Grupo de Estudos em Seguros e Riscos (GESER) na Escola Superior de Agricultura "Luiz \\ de Queiroz" (ESALQ/USP). \\ Rua Sebastião Rodriguês Pinto, 781, bairro Algodoal - CEP: 13405-413 - Piracicaba-SP. \\ mrizato@gmail.com
}

\section{Resumo}

Com a reestruturação da cidade nas últimas décadas, há uma proliferação de subcentros causada por quatro motivos: expansão da área urbana e crescimento demográfico, distância centro-periferia, necessidade das especializações, e as deseconomias externas. O presente trabalho analisa a formação e as características de subcentros comerciais na cidade de Piracicaba - SP.

Palavras-chave: Subcentro; Cidade; Piracicaba.

\begin{abstract}
With the restructuring of the city in recent decades, there is a proliferation of subcenters caused by four reasons: expansion of urban and population growth, distance center-periphery, need for specialization, and the external diseconomies. This paper analyzes the formation and characteristics of commercial sub-centers in the city of Piracicaba - SP.
\end{abstract}

Keywords: Sub-center; City; Piracicaba. 


\section{Resumen}

Con la reestructuración de la ciudad en las últimas décadas, hay una proliferación de sub-centros causada por cuatro razones: la expansión del crecimiento urbano y la población, la distancia de centro-periferia, la necesidad de especialización, y las deseconomías externas. Este trabajo analiza la formación y características de los subcentros comerciales en la ciudad de Piracicaba - SP.

Palabras clave: Sub-centro; Ciudad; Piracicaba.

\section{Introdução}

Segundo Selingardi-Sampaio (1973) até a década de 1950, a produção industrial em Piracicaba/SP era predominantemente alimentícia, todos os produtos eram derivados da cultura canavieira (açúcar, álcool e aguardente), mostrando a grande importância da agroindústria para o município. Após o período em questão, a mecânica e a metalúrgica ganharam destaque no ramo industrial de Piracicaba, ambas ligadas a cultura da canade-açúcar com a produção de máquinas, aparelhos e acessórios para a agricultura, usinas de álcool e destilarias de aguardente. Também os setores, como têxtil, celulose e papel, mobiliário e químico merecem destaque, apesar da baixa porcentagem representativa em relação aos outros setores.

Os setores industriais citados, principalmente mecânica e metalúrgica, são os maiores estabelecimentos, conseqüentemente são os que possuem maior número de empregados, sendo assim, necessitam de mão de obra especializada, uma vez que os funcionários operam complexas máquinas. O Serviço Nacional de Aprendizagem Industrial (SENAI) oferece cursos para tais qualificações e ao longo dos anos várias outras instituições de ensino se instalaram em Piracicaba. A dinâmica e o desenvolvimento econômico da cultura canavieira se intensificaram com o projeto Próálcool (1975), no qual substituía a gasolina por etanol, uma iniciativa do governo devido às altas taxas dos barris de petróleo (Choque do Petróleo - 1973).

Além do expressivo setor industrial, o setor comercial é bastante significativo, uma vez que a conseqüência de uma elevada produção industrial é a comercialização do mesmo. Piracicaba, além de atender a região e a outros estados brasileiros, também, exportava seus maquinários agrícolas para outros países. Conforme a Relação Anual de Informações Sociais (RAIS) - Ministério do Trabalho e Emprego, em 2009, Piracicaba possuía 4.142 estabelecimentos comerciais; 3.395 estabelecimentos de serviços e 1.856 
estabelecimentos industriais. A atividade comercial concentra-se principalmente na área central da cidade e conta com a presença de comerciantes locais e grandes grupos que atuam em escalas estadual e nacional. É importante ainda dizer que Piracicaba, segundo o Sindicado das Indústrias Metalúrgicas, Mecânicas, de Material Elétrico, Eletrônico, Siderúrgicas e Fundições de Piracicaba, Saltinho e Rio das Pedras (SIMESPI), em 2005, contava com 43 agências bancárias que atuam na esfera nacional, caracterizando o município como importante praça financeira regional.

Apesar do município não possuir ligação direta com as principais rodovias do Estado de São Paulo, o mesmo pode ser considerado desenvolvido, por conta de suas indústrias, comércio, serviços e finanças que atendem outros municípios ao seu redor.

Devido ao elevado número de estabelecimentos comerciais na região central do município em questão, observa-se nas últimas décadas um intenso processo de desconcentração nas cidades, podendo ser observado através da criação de subcentros comerciais em bairros residenciais.

Nesse contexto, tendo como referência o processo de desconcentração e o surgimento de novas centralidades no espaço urbano, o objetivo deste trabalho é analisar a formação e as características de subcentros comerciais na cidade de Piracicaba, colocando-se em prática alguns dos conceitos vistos na bibliografia geográfica.

Para isso, foram realizados levantamentos de dados primários e secundários, além de uma revisão acerca de teses que discursam sobre o tema.

Piracicaba, localizada no interior do estado de São Paulo (Figura 1), segundo dados do Instituto Brasileiro de Geografia e Estatística (IBGE), possuía em 2010 um total de 364.872 habitantes, com uma densidade demográfica de 264,98 (hab./km²).

Além dessa parte introdutória, o trabalho está dividido em mais quatro partes. Na primeira etapa é exposto com detalhes à metodologia utilizada na pesquisa. Logo após, apresentamos os pressupostos teóricos vinculados a Geografia Urbana. Na discussão dos resultados é feita uma análise de quatro subcentros piracicabanos (Vila Rezende, Santa Terezinha, Paulista e Piracicamirim). E por fim, nas considerações finais, tentamos consolidar o referencial teórico de acordo com o que foi evidenciado em campo. 


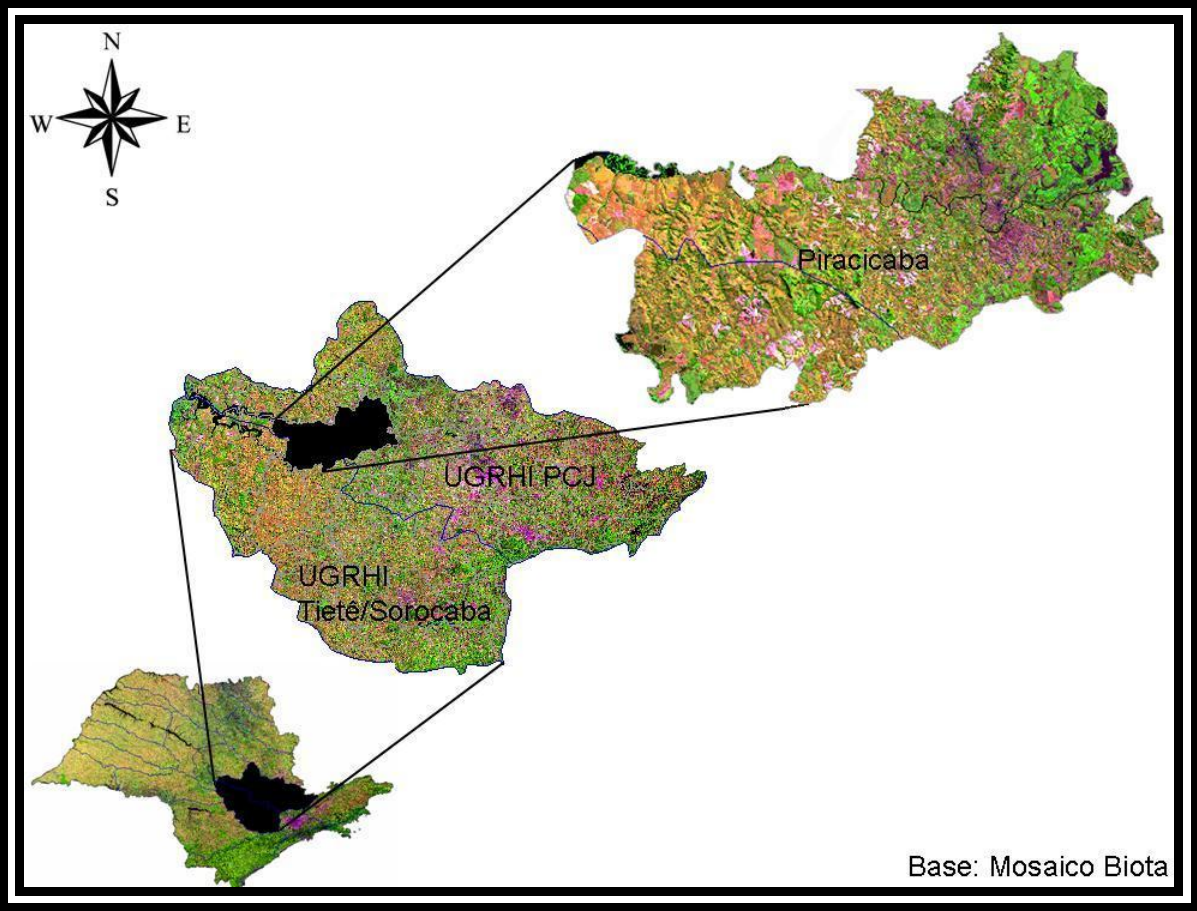

Figura 1. Localização da área de estudo

\section{Metodologia}

Visando entender o funcionamento do processo de formação de subcentros comerciais, inicialmente foi realizada uma revisão bibliográfica, buscando-se em trabalhos científicos idéias e conceitos que pudessem subsidiar o entendimento desse fenômeno no município de Piracicaba/SP.

Posteriormente, houve uma busca em instituições de pesquisas (IBGE e IPPLAP) de dados secundários que auxiliassem na caracterização dos subcentros e dos bairros em que estes se inserem.

Após esse levantamento de dados secundários, foram então realizados trabalhos de campo, onde foram quantificados e classificados todos os empreendimentos comerciais, sendo também levantado a data de abertura dos mesmos, permitindo uma análise temporal. Para a realização da pesquisa de campo, foram selecionadas as ruas e as avenidas de quatro bairros estratégicos, onde o comércio era mais intenso, os quais designamos subcentros.

Assim, foi realizada a análise quali-quantitativa dos subcentros comerciais estudados, sendo organizados croquis e tabelas para um melhor entendimento da formação e caracterização dos mesmos, permitindo então o enquadramento desses com as teorias levantadas nas teses científicas. 
Para a divisão dos estabelecimentos nos subcentros, os mesmos foram divididos em 14 grupos de segmentos comerciais. Os grupos admitidos foram: farmácia, bijouteria, fotografia, alimentação (envolvendo restaurantes e bares em geral), materiais de construção civil, produtos automotivos em geral, tecnologia (envolvendo materias de computador e afins), banco financeiro, ótica e relojoaria, pet shop, presentes, enxoval e setor de serviços. Foram classificados como "outros", os estabelecimentos que são únicos de um segmento nos subcentros.

O esquema da Figura 2 demostra a aplicação da metodologia utilizada para a realização do trabalho.

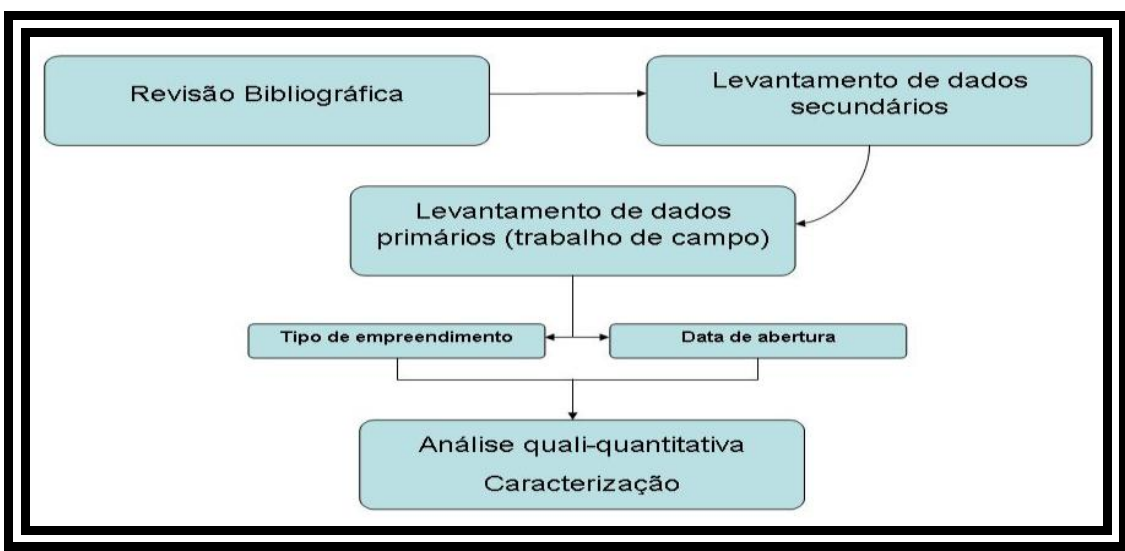

Figura 2. Esquema Metodológico

\section{Pressupostos Teóricos}

Vários autores vêm trabalhando no sentido de procurar entender a formação de subcentros comerciais.

Sposito (2007) compreende que a partir dos anos 80, principalmente, as cidades de porte médio vêm sofrendo um processo de multiplicação de áreas centrais (multicentralidade), como pode se observar na seguinte citação:

... pesquisas apontam para a redefinição das relações entre o centro e a periferia nas cidades de porte médio. Até os anos de 1970 e 1980, a circulação intra-urbana nessas cidades articulava-se em torno de um centro principal, compondo estruturas monocêntricas fortemente integradas a uma única área importante de concentração de estabelecimentos comerciais e de serviços. Nos últimos vinte anos, observou-se multiplicação de áreas de concentração dessas atividades (eixos comerciais, centros comerciais em bairros de bom poder aquisitivo e shopping centers), bem como verificou-se o fenômeno de diversificação delas, acompanhado de segmentação dos 
mercados consumidores, segundo diferentes padrões de consumo e maior ou menor facilidade para se locomover por automóvel (SPOSITO, 2007).

Segundo a autora, esse processo pode ser entendido pelo conceito de reestruturação das cidades, sendo que a reestruturação produtiva no território paulista gerou uma ampliação não apenas demográfica das cidades de porte médio, mas também da capacidade e da qualidade de consumo de seus moradores.

Já Bizerra (2009) explica que a formação dos subcentros em comércio e serviços acontece em bairros residenciais, devido à expansão da área urbana através dos novos loteamentos e dos conjuntos habitacionais formados em conseqüência do crescimento demográfico.

França (2007) apud Marques e França (2010) comenta a questão da formação de subcentros comerciais em relação à distância centro-periferia. Para ele os subcentros em comércio e serviços surgem de maneira espontânea, para suprir as necessidades de infra-estrutura comercial da população de bairros afastados do núcleo central.

Vale também ressaltar Souza e Ribeiro Filho (2009), que apontam os subcentros em comércio e serviços, as vias especializadas em comércio e serviços e os shoppings centers como as formas que a desconcentração assume.

Em relação à desconcentração, podemos também citar como um dos propulsores, as chamadas deseconomias externas, que passam a atuar em situações de demasiada concentração, causando externalidades negativas (deseconomias de aglomeração). Myrdal (1965) explica que um centro de expansão econômica tende a retardar quando tiver alcançado certo nível de desenvolvimento e aglomeração, revertendo o processo de acumulação de capital.

Considerando as idéias levantadas, pode-se concluir que os subcentros podem se formar em diferentes condições e por diferentes fatores, sendo que o presente trabalho procura relacionar essas teorias com os subcentros estudados do município de Piracicaba/SP.

\section{Resultados e Discussão}

Caracterização dos Subcentros 
Para uma caracterização superficial dos subcentros, a princípio, foram utilizados dados secundários dos bairros selecionados: Vila Rezende, Santa Terezinha, Paulista e Piracicamirim.

Tabela 1. Área dos bairros por ocupação - 2009

\begin{tabular}{c|cccc}
\hline Bairro & Região & Ocupada $($ Ha. $)$ & Livre $($ Ha. $)$ & Total $($ Ha. $)$ \\
\hline Vila Rezende & Centro & 153,01 & 0,0 & 153,01 \\
Santa Terezinha & Norte & 249,18 & 171,52 & 420,70 \\
Paulista & Sul & 102,36 & 0,0 & 102,36 \\
Piracicamirim & Leste & 91,55 & 2,93 & 94,48 \\
\hline
\end{tabular}

Fonte: Instituto de Pesquisas e Planejamento de Piracicaba.

Organização: Silas Nogueira de Melo.

Tabela 2. População censitária por bairro - 1991 e 2000

\begin{tabular}{c|ccc}
\hline Bairro & Região & $\mathbf{1 9 9 1}$ & $\mathbf{2 0 0 0}$ \\
\hline Vila Rezende & Centro & 6.896 & 6.382 \\
Santa Terezinha & Norte & 9.626 & 12.099 \\
Paulista & Sul & 10.832 & 9.739 \\
Piracicamirim & Leste & 5.730 & 7.097 \\
\hline
\end{tabular}

Fonte: IBGE - Censo Demográfico 2000

Organização: Silas Nogueira de Melo.

Tabela 3. Densidade demográfica por bairro - 2000

\begin{tabular}{c|cccc}
\hline Bairro & Região & $\begin{array}{c}\text { Total Ocupada } \\
\text { (ha.) }\end{array}$ & $\begin{array}{c}\text { População } \\
\text { Total }\end{array}$ & $\begin{array}{c}\text { Densidade } \\
\text { (hab/ha. })\end{array}$ \\
\hline Vila Rezende & Centro & 152,90 & 6.382 & 41,74 \\
Santa Terezinha & Norte & 239,20 & 12.099 & 50,58 \\
Paulista & Sul & 100,30 & 9.739 & 97,10 \\
Piracicamirim & Leste & 76,70 & 7.097 & 92,53 \\
\hline
\end{tabular}

Fonte: IBGE, Censo Demográfico 2000

Organização: Silas Nogueira de Melo.

Tabela 4. Rendimento dos chefes de família por bairro e faixa salarial - 2000

\begin{tabular}{c|ccccccccc}
\hline \multirow{2}{*}{ Bairro } & \multicolumn{10}{c}{ Faixa Salarial } \\
\cline { 2 - 11 } & Até 1 & De 1 & De 2 & De 3 & De 5 & De 10 a & De 15 & Mais & Total \\
& salário & a 2 & a 3 & a 5 & a 10 & $\mathbf{1 5}$ & a 20 & de 20 & \\
Vila Rezende & 132 & 174 & 236 & 437 & 619 & 192 & 131 & 115 & 2036 \\
Santa & 239 & 473 & 431 & 861 & 812 & 125 & 57 & 38 & 3036 \\
Terezinha & & & & & & & & & \\
Paulista & 260 & 364 & 402 & 685 & 789 & 167 & 107 & 98 & 2872 \\
Piracicamirim & 116 & 223 & 219 & 467 & 579 & 195 & 77 & 54 & 1930 \\
\hline
\end{tabular}

Fonte: IBGE - Censo Demográfico 2000.

Organização: Silas Nogueira de Melo. 
Analisando a Tabela 1 percebe-se que o maior bairro é Santa Terezinha, entretanto, cerca de $40 \%$ de sua área total não é ocupada. Vila Rezende e Paulista, por estarem perto do centro, possuem toda sua área ocupada. E o Piracicamirim, um pouco mais distante do centro, possui 2,93 hectares sem ocupação. Podemos fazer uma relação direta de que quanto maior a proximidade do centro, maior a taxa de desocupação.

A Tabela 2 e a Tabela 3 se complementam, fornecendo respectivamente a população censitária dos bairros e a densidade demográfica. Destaque novamente para Santa Terezinha com maior população, porém, com cerca de 50 habitantes por hectare. Taxa razoavelmente baixa se comparado com os demais bairros, sendo justificado pela sua área de extensão. Mas a menor densidade demográfica é a do bairro Vila Rezende, o que demonstra que o bairro tem um aspecto mais comercial, sendo utilizado durante o dia apenas como o lugar de trabalho dos piracicabanos, sendo que esse tipo de fenômeno é característico da maioria dos centros. Já Paulista e Piracicamirim possuem alta taxa de densidade demográfica, sendo caracterizados como uma centralidade híbrida, com funções comerciais e residenciais.

Na quarta tabela podemos ver os rendimentos dos chefes de famílias dos bairros. De forma mais abrangente, nota-se que nos quatro bairros a maioria dos chefes ganha de 3 a 10 salários. Destacam-se os bairros de Vila Rezende e Paulista, com os maiores rendimentos salariais. Mas, também encontramos, no bairro Paulista, o maior número de chefes, que ganha, até 1 salário, demonstrando possuir a maior desigualdade entre os bairros estudados.

Nos próximos tópicos, serão analisados os quatro bairros, individualmente, de forma mais aprofundada, com um pequeno histórico, croqui e informações geradas através do trabalho de campo.

\section{Subcentro da Vila Rezende}

Começou a crescer em 1881, quando se fundou o Engenho Central, assim transformando-se em um grande pólo de atração de mão de obra. Nessa época, a população predominante no Bairro eram os imigrantes Italianos que vieram para trabalhar no plantio de cana de açúcar.

No início do século, o Barão de Rezende (com o falecimento de sua filha Lídia, em 1909), realizou inúmeras obras, como a Ponte Nova (atual Irmãos Rebouças), a 
Igreja Matriz da Vila Rezende e o Instituto Baronesa de Rezende. Nesse mesmo período, começaram a surgir as indústrias ligadas a atividades canavieiras. Assim, surgiram a DEDINI e as metalúrgicas CSJ e MANTONI.

Hoje, na Vila estão localizadas várias das principais indústrias da cidade, como: a DEDINI, SANTIN, WHITE MARTINS e ainda um comércio dinâmico, com lojas situadas na Avenida Rui Barbosa e nas demais vias do Bairro até o Shopping Piracicaba.

O subcentro da Vila Rezende (Figura 3) é caracterizado como de alta renda e com maior diversidade e número de estabelecimentos. No total, foram contabilizados 99 estabelecimentos comerciais na área de estudo apontado no mapa acima.

Apesar de existir grande diversidade nos segmentos comerciais, dentre as principais atividades existentes, o setor de serviço se destaca como principal, sendo seguido pelo setor de alimentos e tecnologia.

Os tipos dos estabelecimentos e de segmentos que se destacam, como o de serviços e tecnologia, mostram que esse subcentro possui uma clientela de alta renda. Este fato também pode ser confirmado pela quantidade de grandes franquias, 3 no total, e de bancos, 6 no total.

De forma geral, o subcentro da Vila Rezende é o mais antigo dos demais, datando o estabelecimento mais antigo ainda aberto em 1945. No decorrer dos anos, o numero de novos estabelecimentos apresentou crescimento regular, destacando um forte aumento no ano de 2000. No acumulado do período, o crescimento permaneceu constante, mostrando que o subcentro está em fase de expansão e incentivado pela criação de novos estabelecimentos nos últimos anos. $\mathrm{O}$ subcentro pertence à região central de Piracicaba e está localizado à aproximadamente $3 \mathrm{~km}$ ao norte do centro da cidade. 


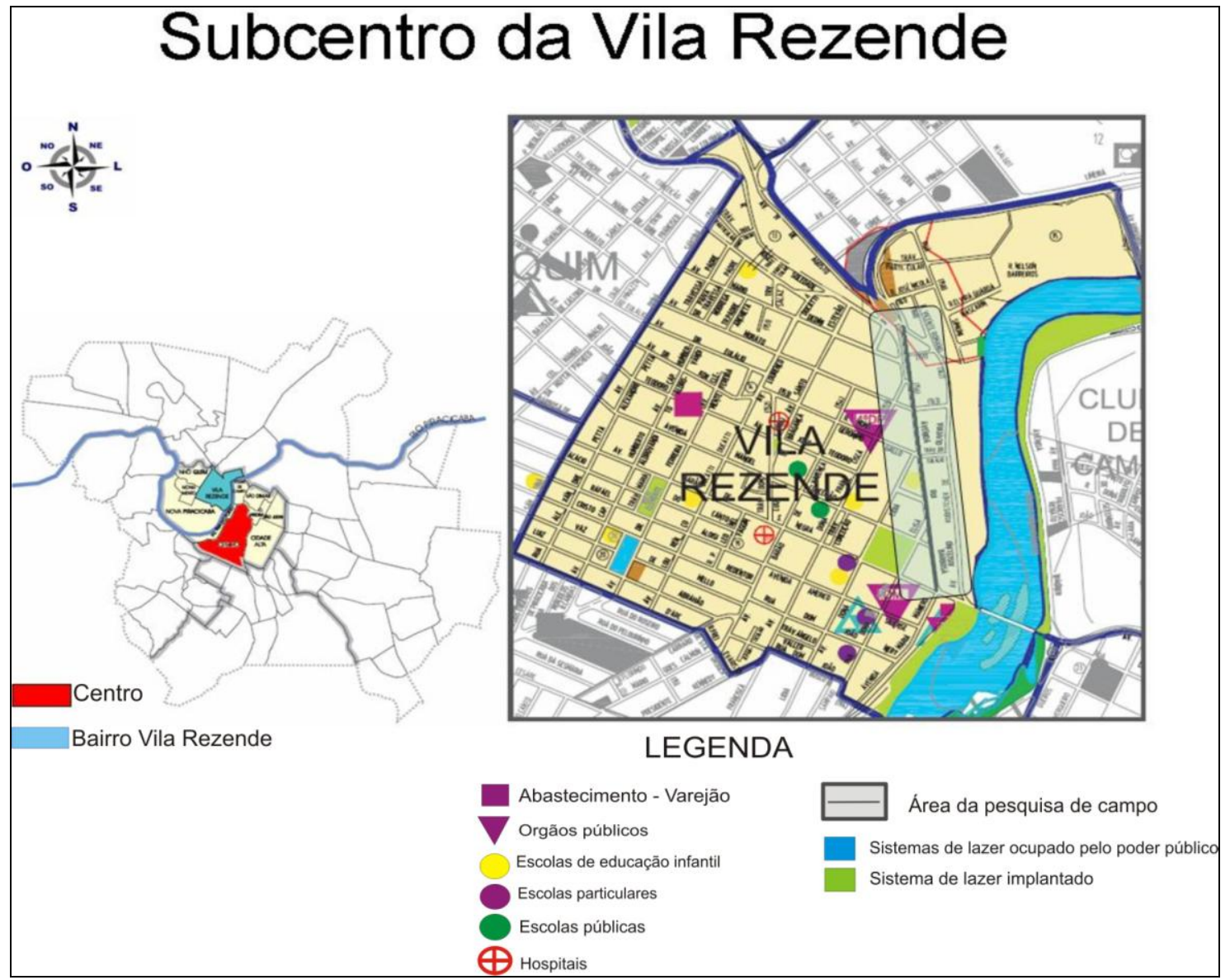

Figura 3. Croqui do Subcentro de Vila Rezende (Fonte: IPPLAP; Organização: Guarda, 2010).

\section{Subcentro da Paulista}

O Bairro, localizado em terras de antiga propriedade do Barão de Serra Negra, Francisco José da Conceição, foi deixado à família em 1883 como herança. O nome do Bairro é decorrência da Estrada de Ferro da Cia Paulista, cuja estação central foi instalada no limite deste com o Centro de Piracicaba.

As negociações para a extensão do Ramal Ferroviário até Piracicaba, datam de 1902, com o ofício enviado à Cia Paulista pelo Dr. Paulo de Moraes. Depois foram feitos estudos para a passagem do ramal férreo. Em 1905 a Câmara adquiriu terrenos para o empreendimento ferroviário, que foi inaugurado no dia 29 de julho de 1922, com a primeira viagem do ramal, entre Santa Bárbara D'Oeste e Piracicaba.

A formação e o desenvolvimento do Bairro se consolidaram naturalmente nas imediações da estação, com a chegada de muitas pessoas, advindas do início do tráfego 


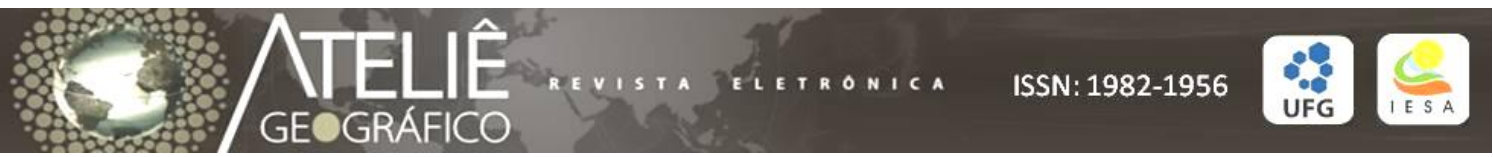

desse ramal, que incentivaram a construção de bares, pensões, restaurantes e hotéis, além da vila ferroviária que atendia aos funcionários da Cia Paulista.

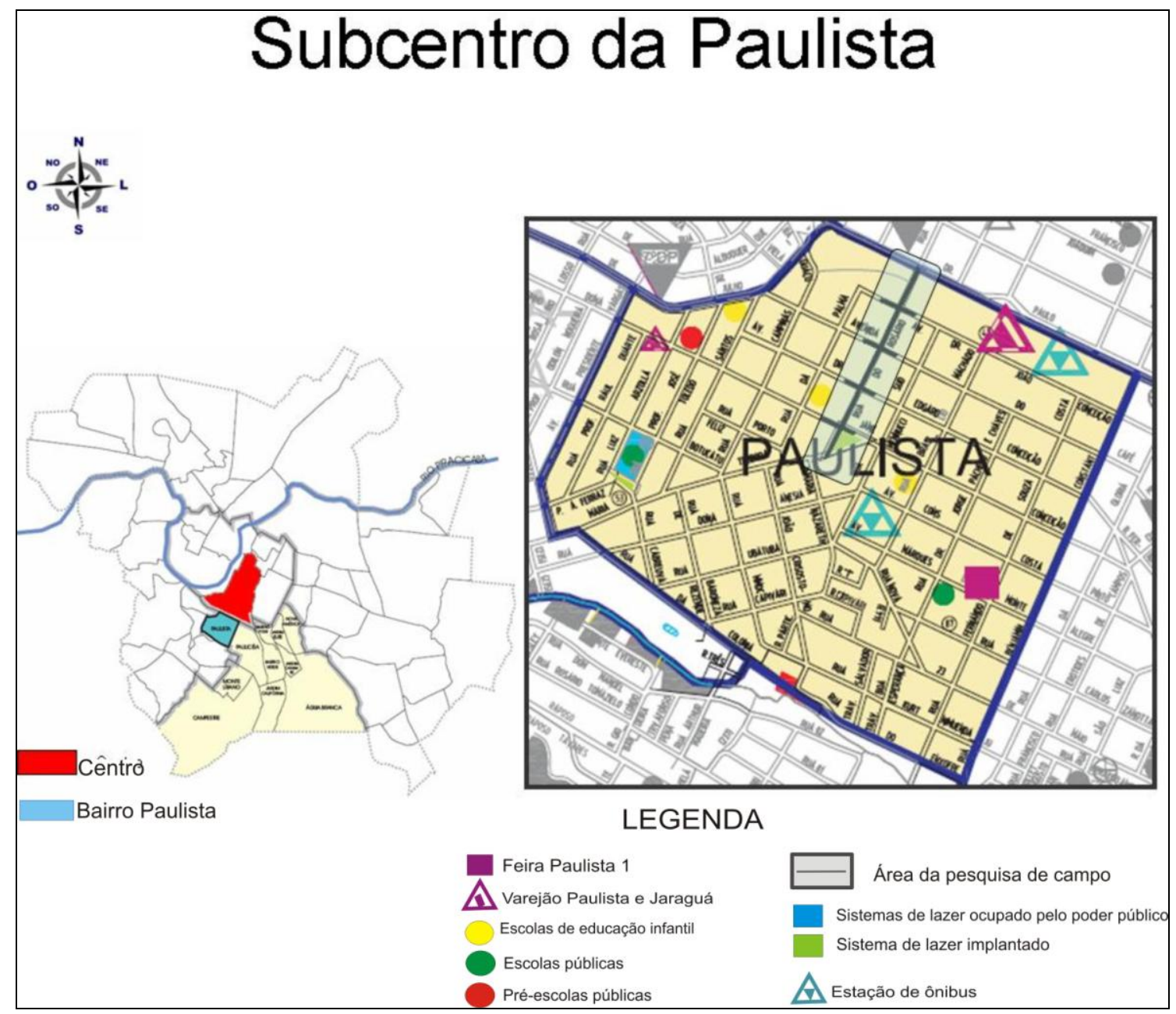

Figura 4. Croqui do Subcentro da Paulista (Fonte: IPPLAP; Organização: Guarda, 2010).

Assim como o da Vila Resende, o subcentro da Paulista (Figura 4) também se caracteriza por uma clientela considerada de alta renda. Contudo, devido a sua maior proximidade com o centro comercial do município, o número total de estabelecimentos e o de diferentes segmentos comerciais é mais reduzido em comparação com o subcentro anterior.

No total são 78 estabelecimentos, onde o setor predominante é o de vestuário, contendo grande número de lojas para um público com maior poder aquisitivo. Em segundo vem o setor de alimentação, seguido pelo setor de serviços. A área estudada também conta com a existência de 4 franquias e de 4 bancos. 
O subcentro da Paulista, data o estabelecimento mais antigo aberto no ano de 1960. De forma geral, a partir deste ano não houve grande crescimento. Contudo, a partir do ano 2000, pode ser notado um notável crescimento na abertura de novos estabelecimentos. Neste caso, o ano onde acontece o maior número de novos estabelecimentos é o de 2010. O subcentro pertence a região sul de Piracicaba e está localizado à aproximadamente $2,5 \mathrm{~km}$ ao sul do centro da cidade.

\section{Subcentro de Santa Terezinha}

Foi fundado em outubro de 1823, com o nome de Corumbataí. Na ocasião do lançamento da pedra fundamental da matriz do Bairro em 1927, passou a ter a atual denominação, a qual foi oficializada em 06 de março de 1935. Em 20 de fevereiro de 1922 foi elevado à categoria de Distrito através da lei número 8092.

Distante do centro de Piracicaba cerca de 10 quilômetros, seu acesso se dá pela Rodovia Geraldo de Barros (SP 304) e Avenida Brasília. O impulso para o seu desenvolvimento populacional foi a instalação de uma usina de açúcar e de várias empresas do ramo papeleiro, alimentício e de um frigorífico. No decorrer dos anos foi recebendo toda a infra-estrutura necessária em transporte, saneamento básico, saúde, educação, iluminação pública e pavimentação.

O subcentro de Santa Terezinha (figura 5) é mais distante do centro da cidade, por isso apresenta o grande número de estabelecimentos comerciais, total de 100 pesquisados. Contudo, a variedade de diferentes segmentos é mais reduzida, sendo basicamente formada pelo setor de vestuários, serviços e alimentação. 


\section{Subcentro de Santa Terezinha}

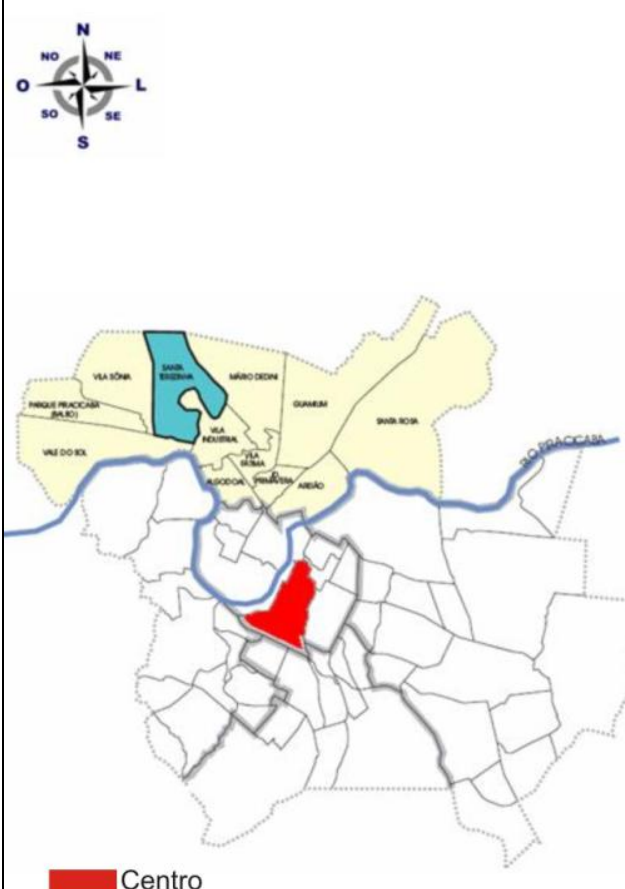

Centro

Bairro Santa Terezinha

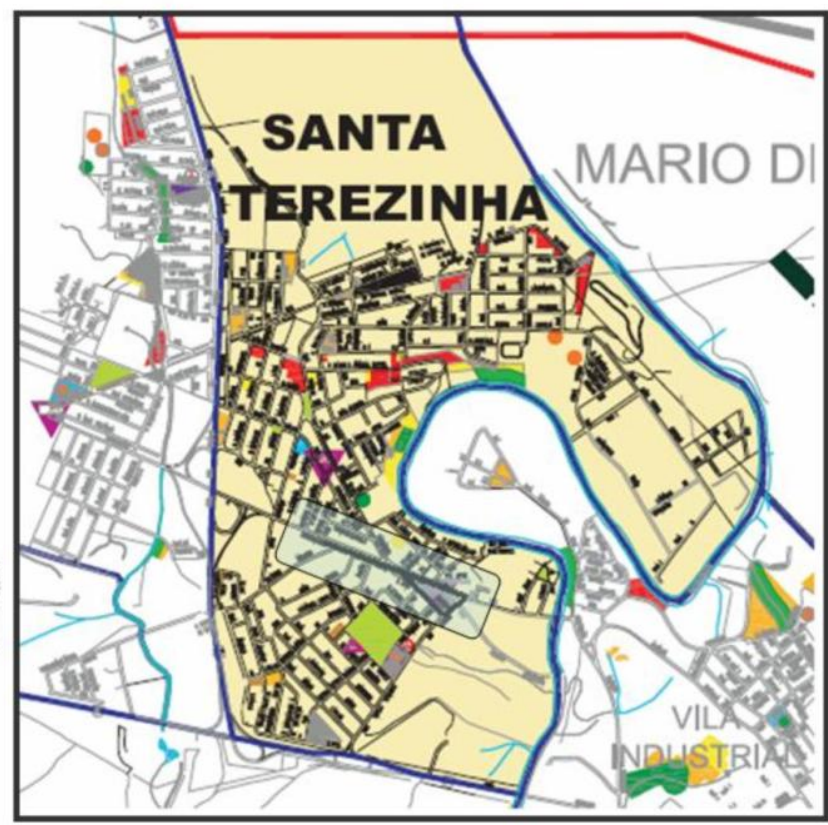

LEGENDA

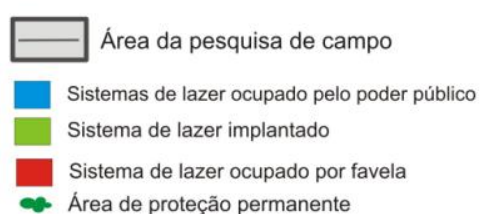

* Área de proteção permanente

Figura 5. Croqui do Subcentro de Santa Terezinha (Fonte: IPPLAP; Organização: Guarda, 2010).

Por ser uma localidade onde a população apresenta menor renda que os demais centros já citados, os estabelecimentos do subcentro de Santa Terezinha são mais simples, voltados à necessidade de uma população que esta situada longe dos principais centros comerciais e necessita de comércios com preços acessíveis para satisfazer as suas necessidades. Nesse sentido, o setor de vestuário, serviços e alimentação acabam sendo mais desenvolvidos nessa localidade. Esse subcentro conta com 2 franquias e 2 bancos.

O subcentro de Santa Terezinha apresenta o estabelecimento mais antigo no ano de 1960. No passar dos anos, a abertura de novos estabelecimentos foi crescente, apresentando um pico no ano de 2009 e 2010, notando a evolução da criação de novas 
unidades comerciais. $\mathrm{O}$ subcentro pertence à região norte de Piracicaba e está localizado à aproximadamente $9 \mathrm{~km}$ ao norte do centro da cidade.

\section{Subcentro do Piracicamirim}

O Bairro Piracicamirim é formado pelos loteamentos Jardim São Simão, Parque Prezotto, Vila Prudente, Cidade Maracanã, Jardim Bandeirantes, Jardim Boa Esperança e Jardim Pombeva. É o subcentro mais recente de Piracicaba, sendo criado pelo crescimento da área urbana do município de Piracicaba que proporcionou desenvolvimento em outras regiões mais periféricas.

O subcentro do Piracicamirim, assim como o de Santa Terezinha, teve a sua evolução totalmente atrelada ao seu distanciamento do centro da cidade. A clientela dos estabelecimentos apresenta médias condições econômicas em relação os demais subcentros estudados neste trabalho.

Maior em número de estabelecimentos, este subcentro apresenta o total de 131 unidades comercias, também situado em uma área maior. Dentre os diferentes segmentos, nota-se a existência de pouca variedade, destacando-se o setor de serviços seguido pelo de alimentação e de produtos automotivos. Piracicamirim conta com 2 franquias e apenas 1 banco dentro da área de estudo.

Apesar de ser o maior, o subcentro de Piracicamirim (Figura 6), é o mais novo, com o estabelecimento mais antigo aberto e datado em 1979.

Com passar dos anos, o crescimento do número de novos empreendimentos foi aumentando, principalmente a partir de 1994, com alguns anos mais fracos. O ano em que houve maior número de novos estabelecimentos foi o de 2001, seguindo a mesma tendência dos demais subcentros comercias estudados. $\mathrm{O}$ subcentro pertence à região leste de Piracicaba e está localizado à aproximadamente $5 \mathrm{~km}$ ao sudeste do centro da cidade. 


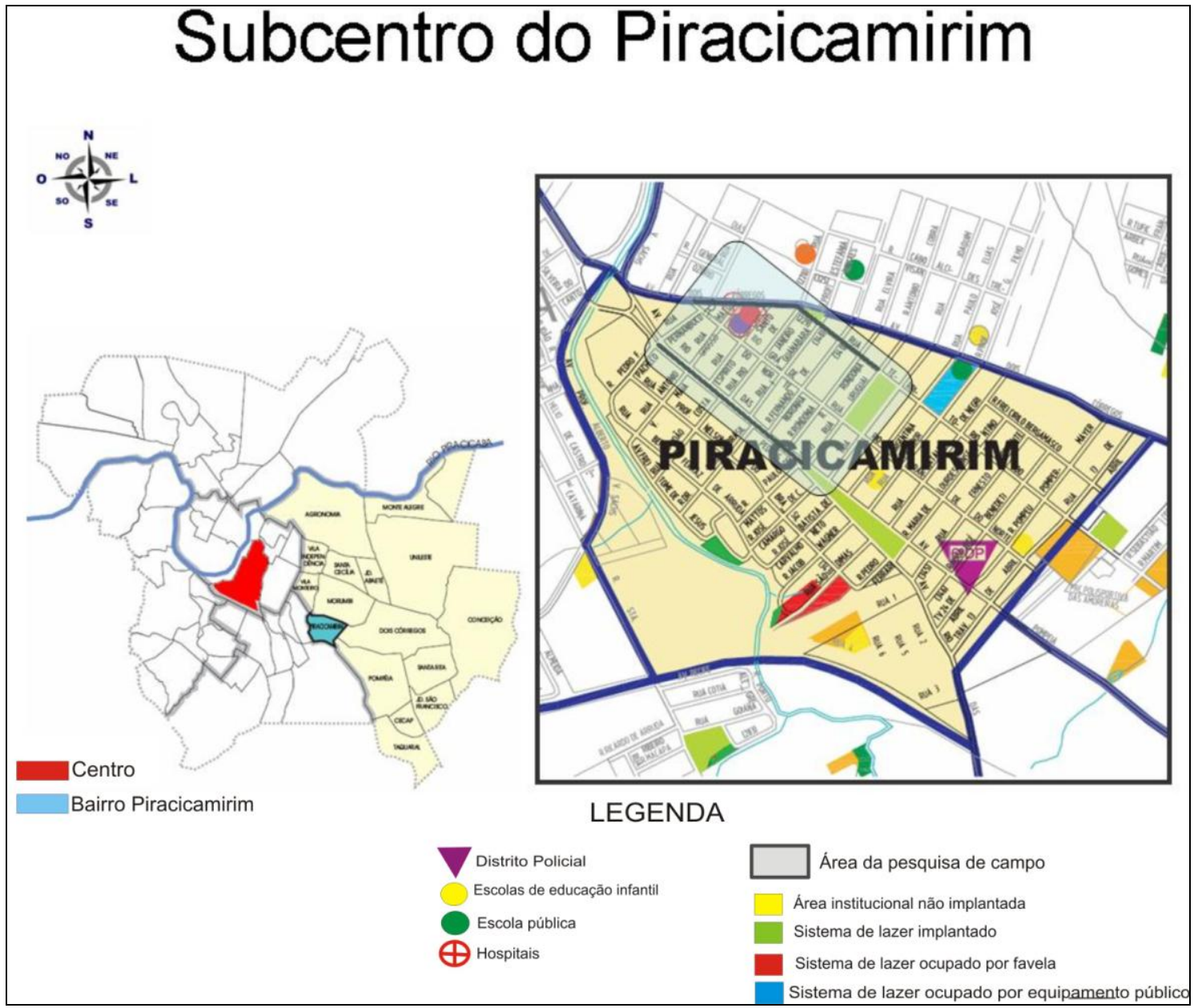

Figura 6. Croqui do Subcentro do Piracicamirim (Fonte: IPPLAP; Organização: Guarda, 2010).

\section{Considerações Finais}

De acordo com o trabalho, pode-se evidenciar que a reestruturação da cidade com a proliferação de novas áreas concentradas aconteceu, principalmente, por quatro motivos: expansão da área urbana e crescimento demográfico; distância centroperiferia; necessidade das especializações; e as deseconomias externas.

Confirmando a hipótese de SPOSITO (2007), os subcentros se diferenciam segundo os padrões de consumo e locomoção, pois ao analisarmos os dados (econômicos, data de fundação dos estabelecimentos e os padrões dos mesmos) referentes aos quatro subcentros de Piracicaba, pudemos concluir que:

1. A criação dos subcentros da Paulista e da Vila Rezende se deu devido ao poder aquisitivo da população e sua facilidade de locomoção através dos automóveis. 
Verifica-se nesses subcentros uma variedade de comércio, serviços e lojas de padrões de consumo de valores maiores.

2. Em Santa Terezinha e Piracicamirim, as evoluções desses centros se deram devido ao distanciamento do Centro da cidade, facilitando aos moradores a compra sem utilização de veículos. Observa-se também em Santa Terezinha, um comércio mais antigo e menos moderno, com lojas de padrão de consumo popular, e grande parte delas sendo de vestuário e calçados.

As atividades comerciais entre os subcentros são bastante semelhantes, pois atendem as necessidades básicas de um indivíduo, como por exemplo: alimentação, vestuário e produtos farmacêuticos. Tais estabelecimentos foram instalados para dinamizar a economia local, conseqüentemente, desconcentrando o comércio da região central de Piracicaba/SP.

Por estar afastado do centro da cidade, o comerciante contribui com impostos mais baixos, ou seja, motivando-o a tal setor. Por outro lado, comércios mais específicos, menos essenciais que os anteriores, tais como: material para construção, material elétrico e material hidráulico também abarcam os subcentros da cidade em questão. Logo, essas atividades comerciais indicam que as construções civis na cidade estão em ascensão, uma vez que a população está crescendo e concomitantemente, elevando o comércio e o consumo.

\section{Referências Bibliográficas}

BIZERRA, Maria Salete da Silva. Desenvolvimento de Subcentros em Bairros Residenciais: Políticas Públicas ou Ações Articuladas dos Moradores? In: SABER ACADÊMICO - n ${ }^{\circ} 07$ - Jun. 2009.

IBGE. Instituto Brasileiro de Geografia e Estatística. Disponível em: (www.ibge.gov.br). Acesso em 25/10/2010.

IPPLAP. Instituto de Pesquisas e Planejamento de Piracicaba. Disponível em: (www.ipplap.com.br). Acesso em 26/10/2010.

MARQUES, Louize Francielly Marques; FRANÇA, Iara Soares de. As Novas Centralidades Urbanas em Cidades Médias: O Subcentro Delfino Magalhães em Montes Claros/MG. In: IV Fórum de Desenvolvimento Regional. Unimontes. Set. 2010. 
MARTINS, L. A. de T. P. Desenvolvimento Econômico e Regional: uma reflexão sobre Piracicaba e região, 1994. $\quad$ Em < www.unimep.br/phpg/editora/revistaspdf/imp24art08.pdf >. Acesso em 26 de jul. De 2010 .

MYRDAL, Gunnar. Teoria Econômica e Regiões Desenvolvidas. Rio de Janeiro: Saga. 1965.

SELINGARDI-SAMPAIO, S. Geografia Industrial de Piracicaba: Um exemplo de interação indústria-agricultura. Tese de Doutorado - Faculdade de Filosofia, Ciências e Letras de Rio Claro, 1973.

SIMESPI. Sindicado das Indústrias Metalúrgicas, Mecânicas, de Material Elétrico, Eletrônico, Siderúrgicas e Fundições de Piracicaba, Saltinho e Rio das Pedras. Disponível em (http://www.simespi.com.br/conheca_piracicaba/numeros.htm). Acesso em $12 / 12 / 2010$.

SINBIOTA. Sistemas de Informações Ambientais do Estado de São Paulo. Disponível em: (www.sinbiota.cria.org.br). Acesso em 04/11/2010.

SOUZA, Marcus Vicícius Mariano; RIBEIRO FILHO, Vitor. O Subcentro Luizote de Freitas em Uberlândia (MG): Novas Centralidades no Contexto das Cidades Médias. Disponível em: (www.observatorium.ig.ufu.br).

SPOSITO, Maria Encarnação Beltrão. Reestruturação Urbana e Segregação Socioespacial no Interior Paulista. In: Anais do $9^{\circ}$ Colóquio Internacional de Geocrítica. Porto Alegre: UFRGS, 2007.

Recebido para publicação em dezembro de 2010 Aprovado para publicação em fevereiro de 2011 